\title{
Viljankorjuun ja varastoinnin simulointi
}

\author{
Pasi Suomi, Timo Lötjönen ja Hannu Mikkola
}

Maa- ja elintarviketalouden tutkimuskeskus, Maatalousteknologian tutkimus (Vakola)

Vakolantie 55,03400Vihti, pasi.suomi@mtt.fi, timo.lotjonen@mtt.fi, hannu.j.mikkola@mtt.fi

\section{Johdanto}

Tutkimuksen "Viljan korjuu ja varastointi laajenevalla viljatilalla" tärkein tavoite oli etsiä keinoja viljankorjuun kustannusten alentamiseen (Suomi ym. 2003). Tutkimus oli jatkoa MTT:ssa 1996 1999 tehdylle tutkimukselle "Viljasadon korjuu ja varastointi" (Haapala ym. 2001). Aiemmassa tutkimuksessa suunnitellun ja rakennetun mallin kehittämistä jatkettiin, koska tilusrakenne haluttiin ottaa mallissa käyttöön juuri sellaisena kuin se on oikeassakin elämässä. Näin saatiin paremmin esille peltolohkojen ja talouskeskuksen välisen liikenteen eli maatilalogistiikan vaikutus työn käyttöön ja kustannuksiin. Parannettua mallia voitiin käyttää myös tutkittaessa tilan laajentamisen rajoja.

\section{Aineisto ja menetelmät}

Viljasadon käsittelyn vaihtoehtoisia ratkaisuja tutkittiin matemaattisen mallin avulla, johon tarvittiin systeemianalyysiä. Kehitetyllä mallilla kuvattiin viljan korjuuseen ja varastointiin liittyviä ratkaisuja. Jotta mallista olisi saatu mahdollisimman tarkka, rajattiin sadonkorjuun ja varastoinnin ulkopuoliset prosessit, kuten muokkaukset, kylvö ja kasvinsuojelu, mallin ulkopuolelle. Tämä on syytä ottaa huomioon mallin antamia tuloksia tarkasteltaessa. Kuitenkin mallissa huomioitiin asioita, jotka eivät suoranaisesti kuuluneet sadonkorjuun aihepiiriin. Esimerkiksi kylvöajankohta ja lajikkeiden ominaisuudet vaikuttavat sadonmuodostukseen ja korjuuajankohtaan, joten ne olivat mukana mallin rakenteessa.

Mallinnukseen ja simulointeihin käytettiin Stella ${ }^{\mathrm{TM}}$ Research 6.0.1 amerikkalaisen High Performance Systems, Inc. yrityksen kehittämää ohjelmaa. Yksi tärkein tavoite mallin kehittämisessä oli tilan lohkoja koskevan paikkatiedon käyttöönotto. Mallissa yksittäisten peltojen sijainti tilakeskuksesta laskettiin ArcView GIS 3.0 ohjelman ja peruskartan avulla. Koska yleisellä tiellä traktorin ajonopeus on suurempi kuin peltotiellä, jaettiin tiestö näihin kahteen luokkaan peruskartan avulla. Yleisellä tiellä traktorin ajonopeus oli $30 \mathrm{~km} / \mathrm{h}$ ja peltotiellä $15 \mathrm{~km} / \mathrm{h}$. Tiestön kunnon vaikutusta korjuu- ja varastointikustannuksiin oli mahdollista tutkia muuttamalla traktorin ajonopeutta. Jos tiestön kunto oletettiin huonoksi, traktorin ajonopeus asetettiin hitaammaksi.

Simuloinnit koostuivat kolmesta osasta. Herkkyysanalyyseillä tutkittiin kuinka malli reagoi tiettyjen parametrien muutoksiin. Toisessa osassa verrattiin vanhaa ja uutta mallia keskenään, jota ei kuitenkaan tässä tekstissä käsitellä. Varsinaiset tutkimukseen liittyvät simuloinnit muodostivat kolmannen osan, joissa pääpaino keskittyi tilusrakenteeseen. Tilusrakennetta koskevissa simuloinneissa tutkittiin tilan lohkokokoon, lohkojen etäisyyden ja tiestön kunnon vaikutusta kustannuksiin. Lisäksi tutkittiin maatilan laajentumista sekä erilaisia kuivuri- ja tuoresäilöntämenetelmiä, koska näiden asioiden uskottiin vaikuttavan korjuu- ja varastointikustannuksiin huomattavasti.

\section{Tulokset ja tulosten tarkastelu}

\section{Herkkyysanalyysit}

Peruslähtökohta herkkyysanalyyseissä oli 120 hehtaarin tila, jossa oli ohraa 48 ha, kauraa 24 ha, kevätvehnää 24 ha, syysvehnää 12 ha ja ruista 12 ha. Tilalla oli töissä kaksi henkilöä, koneina kaksi traktoria, kaksi perävaunua ja leikkuupuimuri, jonka leikkuuleveys oli $360 \mathrm{~cm}$. Lämminilmakuivurin koko oli $30 \mathrm{~m}^{3}$. Mallin herkkyyttä testattiin muuttamalla puimurin lohkonvaihtoon kuluvaa aikaa, polttoöljyn hintaa sekä vaihtamalla traktorin maantie- ja peltotienopeutta.

Puimurin lohkonvaihdon hidastuessa 10 minuutista 30 minuuttiin, kustannukset alkoivat nousta. Lohkonvaihtoon kuluvan ajan pidentyessä ajallisuuskustannus kasvoi ja kuivaustunnit alenivat, koska osa viljasta jäi peltoon varisemisen takia. Polttoaineen hinta oli noussut vuodesta 2000 vuoteen 2002 $11,1 \mathrm{snt} / \mathrm{l}$. Kahden vuoden aikana tapahtunut hinnan nousu kohotti korjuun ja varastoinnin kustannusta esimerkkitilalla 3,4 $€$ /tonni. Traktorin ajonopeuden avulla simuloitiin tiestön vaikutusta kustannuksiin. Alhaisen ajonopeuden aiheuttama traktorin käyttötuntien nousu ei kasvattanut kustannuksissa kuin nimellisesti. Kustannuksia nosti polttoaineen kulutuksen, traktorin käyttötuntien ja työtuntien kasvu. Simulointien mukaan tiestöllä ei kuitenkaan ollut merkittävää vaikutusta kustannuksiin esimerkkitilalla. Herkkyysanalyysit vahvistivat käsityksen siitä, etteivät lohkonvaihtoon kuluva aika ja tiestön kunto 
merkittävästi vaikuta viljan korjuu- ja varastointikustannukseen. Tiestön kunto on siis enemmänkin mukavuus- ja turvallisuustekijä kuin kustannustekijä. Teiden huono kunto voi aiheuttaa koneiden rikkoutumisia ja vaaratilanteita, jotka eivät näy simulointien tuloksissa.

\section{Tilan lohkokoon vaikutus korjuukustannuksiin}

Tutkittaessa lohkokoon vaikutusta kustannuksiin, oli peruslähtökohtana 50 hehtaarin virtuaalitila, jossa oli 20 ha ohraa, 15 ha kauraa ja 15 ha kevätvehnää. Ohralohkon etäisyys talouskeskuksesta oli 350 $\mathrm{m}$, kevätvehnälohkon $1 \mathrm{~km}$ ja kauralohkon $5 \mathrm{~km}$. Tilan konekapasiteetti oli hieman ylimitoitettu, koska se mitoitettiin 70 hehtaarin tilan mukaan. Lohkokokoa käsittävät simuloinnit tehtiin vaiheittain. Ensimmäisessä vaiheessa jokainen viljalaji oli yhtenä lohkona, jonka jälkeen ne jaettiin osiin. Lopulta neljännessä vaiheessa lohkoja oli $24 \mathrm{kpl}$.

Lohkojen koko tai etäisyys ei juurikaan vaikuttanut korjuukustannuksiin, kun sadonkorjuusää oli hyvä. Sadonkorjuusään ollessa huono, kustannustaso oli kaikissa simuloinneissa vähintään $16 € /$ tn korkeampi kuin hyvän sään vallitessa. Ero johtuu pääosin viljan varisemisen ja laadun heikkenemisen aiheuttamasta ajallisuuskustannuksesta. Huonon korjuusään vallitessa, keskimääräisen lohkokoon pieneneminen alle 4,20 hehtaarin lisäsi kustannuksia $3 \%$. Sää vaikuttaa siis kustannuksiin selvästi enemmän kuin lohkokoko ja etäisyys. Huono lohkorakenne ja etäisyys korostavat sään vaikutusta. Huonon sään vaikutus voi olla simuloitua suurempi, koska malli ei ota huomioon sadekatkojen aiheuttamaa lisätyötä. Työn organisointi vaikeutuu ja viljelijä joutuu olemaan koko ajan valmiina puinnin jatkamiseen, mikä haittaa muiden töiden tekemistä.

\section{Tilan lohkojen etäisyyden vaikutus korjuukustannuksiin}

Lohkojen etäisyyksien vaikutusta kustannuksiin tutkittiin käyttäen samaa virtuaalitilaa kuin simuloitaessa lohkokokoa. Tilan kauralohkojen etäisyyttä kasvatettiin $5 \mathrm{~km}$ :stä aina $40 \mathrm{~km}$ :iin. Käytettäessä hyvää sadonkorjuusäätä, etäisyys ei vaikuttanut kustannuksiin viljan korjuu- ja varastoinnin kustannuksen ollessa silloin 100,9 €/tonni. Käytettäessä huonompaa sadonkorjuusäätä ja kun tilalla työskenteli 2 henkilöä, kustannukset kasvoivat vasta kun etäisyys oli $40 \mathrm{~km}$. Kun tilalla työskenteli yksi henkilö, puintikausi piteni ja kustannukset nousivat lähinnä ajallisuuskustannuksen takia. Kun kauralohkojen etäisyys talouskeskuksesta oli $40 \mathrm{~km}$ ja tilalla työskenteli yksi henkilö, kustannukset nousivat aina $127,8 €$ viljatonnia kohden. Simuloinneissa oletettiin, että puimurilla ajettiin vain kerran alueelle jossa lohkot sijaitsivat. Näin kustannusten nousu johtui lähes kokonaan viljan siirtoajon kasvaneista kustannuksista.

\section{Tilan laajentuminen}

Tilan laajentumista simuloitiin edelleen virtuaalitilan avulla. Esimerkkitilan peltopinta-alaa kasvatettiin vaiheittain 5 ja 10 hehtaarin bhkolla sekä 30 hehtaarin alueella, joka oli jaettu neljään lohkoon. Lohkojen etäisyyttä vaihdeltiin 5-40 km:iin. Ennen laajennusta korjuu- ja varastointikustannus oli 100,9 €/tonni. Kun viljatila laajentui 5 hehtaarilla, kustannus aleni 6,7 €/tonnia. Vastaavasti 10 hehtaarin laajennus alensi kustannuksia 11,8 €/tonnia. Kuten edellä todettiin, lohkojen etäisyydellä ei ollut merkittävää vaikutusta viljan korjuu- ja varastointikustannuksiin. Tämä pätee myös 5 ja 10 hehtaarin lisämaan hankinnassa. Kun tilan pinta-alaa kasvatettiin 30:1lä hehtaarilla, kustannus hyvällä sadonkorjuusäällä oli $79 €$ /tonni. Huonommalla säällä kustannukset kohosivat lähinnä ajallisuuskustannusten takia. Myös alueen etäisyydellä oli pieni merkitys kustannuksiin. Laajentamalla kustannukset saadaan alenemaan, mutta suurehkon lisäalueen (30 ha) etäisyyden kasvaessa yli 30 kilometrin kustannukset alkavat jälleen kohota.

\section{Tilojen verkottuminen}

Koska tilojen välisen yhteistyön avulla on mahdollista alentaa kustannuksia, simuloitiin mallin avulla myös tilojen verkottumista. Yhteistyötä koskevat simuloinnit tehtiin kolmen todellisen maatilan avulla. Tilalla A oli viljelyksessä 47,8 ha, tilalla B 17 ha ja tilalla C 13 ha. Ensimmäisessä vaiheessa simuloitiin erillisten tilojen korjuu- ja varastointikustannukset. Tilalla A työskenteli kaksi henkilöä, tiloilla $\mathrm{B}$ ja $\mathrm{C}$ yksi henkilö. Toisessa vaiheessa tilat yhdistettiin. Uusi talouskeskus suunniteltiin tilan B paikalle, koska tila on keskeisellä paikalla ja kyseisellä tilalla oli suurin kuivuri. Konekannaksi valittiin tilojen uusimmat ja suurimmat koneet. Esimerkiksi puimuri oli tilalta A. Yhteistyötilalla työskenteli kaksi henkilöä. 
Tilan A korjuu- ja varastointikustannus oli $\mathbf{6 5 , 6} € /$ tonni. Tilalla B kustannus oli $\mathbf{9 2 , 5} € /$ tonni ja tilalla C 116 €/tonni. Vaikka tilan A konekanta oli uusin ja kiinteät kustannukset korkeimmat, kustannukset olivat huomattavasti alhaisemmat viljatonnia kohden kuin muilla tiloilla. Tämä johtui tilan A suurimmasta pinta-alasta, jolloin kustannukset jakautuivat isomman viljamäärän kesken. Tilan A työtunnit olivat huomattavasti korkeammat kuin tilojen B ja C, koska tilalla työskenteli kaksi henkilöä. Tilat B ja C olivat viljelyalaltaan ja konekannaltaan lähes saman suuruiset. Kuitenkin tilalla C kustannus oli huomattavasti korkeampi kuin tilalla B. Pienillä tiloilla muutamankin hehtaarin vilja-alan lisäys alentaa merkittävästi kilokohtaista kustannusta

Tilojen välisellä yhteistyöllä korjuu- ja varastointikustannus aleni $\mathbf{5 3 , 8}$ euroon/tonni. Olemassa oleva konekapasiteetti riitti hyvin uuden verkostotilan tarpeisiin. Ajallisuuskustannus ja kiinteät kustannukset eivät nousseet tilan A tasosta merkittävästi. Simulointien mukaan pienimmät tilat hyötyivät eniten yhteistyöstä. Esimerkiksi tilan C kustannus puolittui yhteistyön ansiosta. Malli ei ota huomioon yhteistyön tarjoamaa työvoiman käyttömahdollisuutta tiloille. Esimerkiksi tila A voisi hyödyntää pienempien tilojen ammattitaitoisia henkilöitä. Joissain tilanteissa sillä saattaa olla paljonkin merkitystä.

\section{Kuivaus- ja säilöntämenetelmien vertailu}

Kuivaus- ja säilöntämenetelmien vertailussa tilalla viljeltiin 72 ha rehuohraa ja 48 ha kauraa. Vertailussa oli perinteinen pakettikuivaamo (kuivaamo 1), jossa kuivaamorakennus muodostuu neliöpohjaisista, suhteellisen pienistä varastosiiloista $(19 \mathrm{kpl})$ ja näiden päälle tehdystä katosta. Varastosiilot ovat alta tyhjennettäviä ja ylipainetoimisen uunin maksimilämpö on $80^{\circ} \mathrm{C}$. Kuivaamot $2-4$ olivat alipaineis ia kuumailmakuivureita, joissa uunin maksimilämpö on $100{ }^{\circ} \mathrm{C}$. Kuivaamon 2 rakenne oli muilta osin sama kuin kuivaamon 1. Kuivaamossa 3 kuivurirakennus koostuu tasamaalla olevista kartiopohjaisista pyörösiiloista $(7 \mathrm{kpl})$, jotka ovat tilavuudeltaan selvästi sompia kuin kuivaamoissa 1 ja 2. Siilojen yhteistilavuus on kuitenkin kaikissa kuivaamoissa sama. Katto on rakennettu siilojen päälle. Kuivaamon 4 kuivurikoneisto on sijoitettu yhteen pyörösiiloon ja vilja varastoidaan sen ympärillä olevaan neljään suurikokoiseen pyörösiiloon. Jokaisessa siilossa on oma kattonsa. Kuivaamon 5 rakenteita on karsittu eniten, siinä kuivurikoneisto on rakennettu säänkestäväksi, jolloin se ei tarvitse ympärilleen suojarakennusta ja kattoa. Vertailussa simuloitiin myös tuoresäilöntää ja kylmäilmakuivausta.

Normaalin lämminilmakuivauksen korjuu- ja varastointikustannus oli suurin. Käytettäessä korkealämpöistä alipainekuivausta kokonaiskustannus oli hieman alhaisempi kuin normaalin lämminilmakuivauksen. Tämä johtui alhaisemmista investointikustannuksista (pois lukien esimerkkikuivaamo 2) ja muuttuvista kustannuksista. Muuttuvien kustannusten säästö johtui pienemmästä polttoöljyn kulutuksesta. Vaikka kuivaamon 2 investointikustannus oli hieman kalliimpi, alhaisempien muuttuvien kustannusten ansiosta viljan korjuun ja varastoinnin kustannukset olivat alemmat kuin kuivaamon 1. Kuivaamot 45 ovat selvästi muita edullisimpia, mutta niiden käyttöominaisuudet eivät ole yhtä hyvät, koska siiloja on vähän ja niiden tyhjennys ei ole yhtä helppoa kuin muissa esimerkkikuivaamoissa. Simulointien mukaan lämminilmakuivurien ja kylmäilmakuivurin ajallisuuskustannukset olivat samat. Voisi olettaa, että alipaineistettujen kuumailmakuivureiden ajallisuuskustannus olisi tehokkuuden ansiosta pienempi. Näin ei kuitenkaan ollut, koska normaalikuivuri ja kylmäilmakuivuri ehtivät kuivata ja varastoida viljan yhtä nopeasti kuin alipainekuivurit. Kylmäilmakuivauksen muuttuvat kustannukset nostivat sen kokonaiskustannuksia. Tällä tilakoolla (120 ha) se on epäkäytännöllinen ratkaisu, koska viljaa joudutaan siirtämään kuivauslaareista varastoon ja se nostaa kustannuksia.

Verrattaessa tuoresäilöntämenetelmien kustannuksia, ilmatiivissäilöntä oli tällä tilakoolla edullisin. Kiinteät kustannukset ovat samaa tasoa kuin murskesäilönnässä, mutta ilmatiiviin säilönnän muuttuvat kustannukset ovat alhaisemmat. Jyväsäilönnän kiinteät kustannukset ovat alhaisimmat, mutta propionihappo nostaa kokonaiskustannuksia. Maatilalla saattaa olla mahdollista toteuttaa jyvä- tai murskesäilöntä pienin investoinnein, mikäli varastona voidaan hyödyntää olemassa olevia rakennuksia. Tätä mahdollisuutta ei ole näissä laskelmissa käytetty. Murskesäilönnän etuna on, ettei viljaa tarvitse jauhaa tai litistää varastoinnin jälkeen, toisin kuin jyvä- tai ilmatiiviissä säilönnässä. Lisäksi viljan korjuu voidaan aloittaa hyvissä ajoin, koska viljan kosteuden on oltava 35-45 \%. Laakasiiloihin investointi nostaa menetelmän kustannuksia, mutta siitä huolimatta se on kilpailukykyinen lämminilmakuivaukseen verrattuna. Tuoresäilöntämenetelmien alhainen ajallisuuskustannus johtuu järkevistä tuoresäilöntäketjuista ja aikaisemmasta sadonkorjuusta. 


\section{Johtopäätökset}

Viljantuotannon pääomakustannukset ovat korkeat. Tilojen verkottuminen tarjoaa usein hyvät mahdollisuudet kiinteiden kustannusten jakamiseen. Edellisellä simulointimallilla tehdyt simuloinnit osoittivat, että urakoijan käyttö puinnissa on edullista yllättävän isollakin tilalla (Haapala ym. 2001). Tämän tutkimuksen simulointien mukaan kolmen tilan yhteistyö puinnissa ja kuivauksessa toi huomattavia kustannussäästöjä varsinkin pienimmille tiloille, vaikka kuljetukset tilojen välillä lisääntyivät. Verkottumisen avulla osakkaat pääsevät hyötymään uusista teknologioista ja he voivat tarjota ammattitaitoaan koko verkon käyttöön.

Tulosten mukaan viljan kuljetus pellolta varastointipaikalle ei näyttäisi olevan kovin suuri logistinen onge lma. Viljan kuljetus ei ole yleensä pullonkaula, mikäli perävaunuja on tarpeeksi, niiden koko on riittävä ja tiestö on hyvässä kunnossa. Korjuu- ja varastointikustannukset eivät simulointien mukaan nousseet merkittävästi, vaikka joidenkin puintilohkojen etäisyyttä varastointipaikasta kasvatettiin aina 40 kilometriin asti.

Simulointien mukaan viljan säilöntä tuoreena on yleensä kuivausta edullisempaa, mikäli viljan kosteus ei ole este sen jatkokäytölle. Tuoresäilöttävän viljan puinti päästään aloittamaan aiemmin kuin kuivattavan viljan puinti, mikä saattaa lisätä korjuuketjun kapasiteettia ratkaisevasti. Ruokintalaitteissa on ollut jonkin verran toimintahäiriöitä talvella kosteaa viljaa käytettäessä, mutta ketjun osien oikealla valinnalla ne voidaan välttää (Palva \& Siljander-Rasi 2003).

Suurin osa lämminilmakuivauksen kustannuksista on kiinteitä, siis kuivurirakennuksesta ja koneistosta johtuvia, joten uutta kuivaamoa hankittaessa säästöjä kannattaa etsiä näistä. Kuivaamon katosta ja seinistä luopumalla ja tinkimällä varastosiilojen määrästä voidaan säästää jopa $35 \%$ kuivaamon hankintahinnasta. Tällaisessa ratkaisussa kuitenkin käyttömukavuus kärsii, joten se ei sovellu kaikille viljelijöille.

Suomalaista maataloutta moitittiin takavuosina yli-investoinnista ja tutkimuksissa todettiin koneiden käyttömäärät alhaisiksi. Nyt olisi sopiva aika selvittää, onko viljan hinnan lasku ja ajallisuuskustannuksen pieneneminen realisoitunut parempana kapasiteetin käyttöasteena. Tilakoon kasvun pitäisi vaikuttaa samaan suuntaan kuin ajallisuuskustannuksen aleneminekin. Onko löysät jo karsittu pois ja voidaanko puheet joutokäynnistä lopettaa?

\section{Kirjallisuus}

Suomi, P., Lötjönen, T., Mikkola, H., Kirkkari, A. \& Palva, R. 2003. Viljan korjuu ja varastointi laajenevalla viljatilalla. Maa- ja elintarviketalous 31. Helsinki. $100 \mathrm{~s}+$ liitteet. ISBN 951-729797-1

Haapala, H., Lötjönen, T., Mikkola, H., Aho, J., Sarin, H., Kivinen, T. \& Alakomi, T. 2001. Viljasadon korjuu ja varastointi. Vakolan tutkimusselostus 78. Vihti: MTT. $63 \mathrm{~s}$.

Palva, R. \& Siljander-Rasi, H. 2003. Kuivaamaton ohra lihasikojen ruokinnassa - toimiva ketju siilosta ruokintaan. Työtehoseuran maataloustiedote 553. Helsinki: TTS. 6 s. 